\title{
Innate immunity and regulatory T-cells in human Chagas disease: what must be understood?
}

\author{
Renato Sathler-Avelar, Danielle Marquete Vitelli-Avelar, Andréa Teixeira-Carvalho, \\ Olindo Assis Martins-Filho/+
}

Laboratório de Biomarcadores de Diagnóstico e Monitoração, CPqRR-FIOCRUZ, Av. Augusto de Lima 1.715, 30190-002 Belo Horizonte, MG, Brasil

\begin{abstract}
There is a general consensus that during chronic Trypanosoma cruzi infection, the host immune system induces complex processes to ensure the control of parasite growth while preserving the potential to mount and maintain a life-long controlled humoral and cellular immune response against the invading pathogen. This review summarises evidence in an attempt to elucidate "what must be understood" to further clarify the role of innate immunity in the development/maintenance of clinical Chagas disease and the impact of etiological treatment on host immunity, highlighting the contributions of the innate immunity and regulatory $T$ (Treg) cells. Recently, increasing focus on innate immunity suggest that chronic $\mathrm{T}$. cruzi infection may cause morbidity when innate effector functions, or the down-regulation of adaptive regulatory mechanisms are lacking. In this context, stable asymptomatic host-parasite interactions seem to be influenced by the effector/regulatory balance with the participation of macrophages, natural killer (NK) and $C D 8^{+} T$ cells in parallel with the establishment of regulatory mechanisms mediated by NKT and Treg cells. Moreover, a balanced innate immune activation state, apart from Treg cells, may play a role in controlling the adverse events triggered by the massive antigen release induced by trypanosomicidal agents during Chagas disease etiological treatment.
\end{abstract}

Key words: human Chagas disease - innate immunity - regulatory T-cells

Chagas disease, caused by the haemoflagellate protozoan Trypanosoma cruzi, is one of the most important public health problems in Latin America, affecting approximately eight million people in South and Central America and a further 100 million people are considered at risk (Weekly 2007). In humans, T. cruzi infection usually develops from an oligosymptomatic acute phase to a possibly debilitating chronic phase that can manifest itself in a variety of ways. A majority of the patients that progress to the chronic phase remains clinically asymptomatic for many years, with no clinical, radiological or electrocardiographic manifestations of cardiac or digestive involvement. These conditions characterise the initial stage of the indeterminate form, known as earlyindeterminate disease, which is usually detected in infected children and adolescents, and late-indeterminate disease, generally observed in infected adults (SathlerAvelar et al. 2003, Vitelli-Avelar et al. 2006). Approximately $30-40 \%$ of infected individuals progress to disease associated with cardiac and/or digestive symptoms (Umezawa et al. 2000). An abnormal electrocardiographic profile, with important alterations in the elec-

Financial support: CNPq (478034/2006-7), FAPEMIG, FIOCRUZ (PAPES V - 403518/2008-3)

+ Correponding author: oamfilho@cpqrr.fiocruz.br

Received 1 April 2009

Accepted 11 May 2009 trical conduction system and/or ventricular arrhythmias are the major features of cardiac patients (CARD), while individuals with digestive disease present with striking luminal enlargement, inflammatory infiltrates in layers of muscle and nervous plexuses (Bonney \& Engman 2008, da Silveira et al. 2008).

The specific mechanisms associated with the establishment and maintenance of these distinct clinical outcomes seems to be multifactorial and involve both parasite and host features (Dutra et al. 2005). The reasons why only a percentage of chronically infected individuals develop severe forms of the disease and why clinical manifestations are highly heterogeneous are still unclear. Currently, many investigators are on their way to answering these questions (Dutra et al. 2005, VitelliAvelar et al. 2005, 2006, 2008, da Silveira et al. 2008). Molecular genetic analyses of different $T$. cruzi isolates have demonstrated that the parasite populations are extremely polymorphic (Buscaglia \& Di Noia 2003). Interestingly, the presence of distinct parasite populations has been correlated with the pathology observed in the different clinical forms of Chagas disease (Vago et al. 2000), suggesting that genetically distinct populations display characteristic tissue tropism and, thus, may be influencing disease outcome (Macedo et al. 2004). The observation that genetically similar parasite isolates can be obtained from patients with distinct clinical forms of the disease suggests that the host immune response may represent an important factor in determining the fate of infection (Vago et al. 2000, Macedo et al. 2004). It is well accepted that the absence of chagasic pathology is 
mainly associated with the ability of infected hosts to regulate the anti-T. cruzi immune response. However, this response, which controls persistent parasitemia, also contributes to the inflammatory collateral damage that causes Chagas disease morbidity.

With the aim of contributing to this field of investigation, studies have been developed to characterise immunological biomarkers in patients presenting distinct clinical manifestations of the disease (Reis et al. 1993, Dutra et al. 1994, 1996, Lemos et al. 1998, Gomes et al. 2003, 2005, Sathler-Avelar et al. 2003, Souza et al. 2004, Vitelli-Avelar et al. 2005, 2006, 2008). Additionally, other investigators have also focused on what impact etiological treatment with benznidazole $(\mathrm{Bz})$ may have on the anti-T. cruzi immune response (Bahia-Oliveira et al. 2000, Sathler-Avelar et al. 2006, 2008, Vitelli-Avelar et al. 2008). These studies are of great interest and may increase our knowledge of the immunological complexities that drive the course of Chagas disease, as well as the immunological events that are triggered by the specific chemotherapy. Understanding the immunological mechanisms involved in the development of chagasic cardiac/digestive disease and the control of parasite replication may contribute to the establishment of new immune intervention approaches to prevent Chagas disease and to treat its symptomatic forms.

This review intends to assemble some of the major findings regarding the immunological features associated with early indeterminate and late chronic stages of human Chagas disease, before and after etiological treatment. Additionally, we focus on aspects of the innate immune response and regulatory $\mathrm{T}$ (Treg) cells, which may lead to new insights on human T. cruzi infection.

\section{Innate immune response during early stages of Cha- gas disease}

Infection by T. cruzi simultaneously triggers multiple compartments of the innate and adaptive immune system. It has been proposed that the strong immune stimulation and the intense inflammatory process elicited during early infection by $T$. cruzi may not only be a major determinant of the immunopathology associated with late disease, but could also be a crucial factor in confining the etiological agent to an intracellular site, thus limiting life-long infection (and its symptomatic consequences) and preventing tissue damage (HontebeyrieJoskowicz \& Minoprio 1991, Samudio et al. 1998, Marinho et al. 1999, Teixeira et al. 2002). Despite the fact that experimental murine models have provided relevant findings concerning the immunological system during early infection with T. cruzi (Brener \& Gazzinelli 1997), the precise mechanism for the initial activation of the innate immune system in humans is poorly understood.

Sathler-Avelar et al. (2003) have demonstrated that early acute human Chagas disease is not associated with monocyte activation or changes in natural killer (NK) cells. However, late acute disease is characterised by a selective increase in a distinct lineage of NK cells $\left(\mathrm{CD} 16^{+} \mathrm{CD} 56^{-}\right)$, whereas patients with early indeterminate Chagas disease show increased expression of HLA-
DR by monocytes. Vitelli-Avelar et al. (2006) further confirmed these findings, demonstrating that the expansion of NK cells $\left(\mathrm{CD} 16^{+} \mathrm{CD} 56^{-}\right)$before the development of $\mathrm{T}$ cell-mediated immunity is a hallmark of early human chronic T. cruzi infection. Furthermore, VitelliAvelar et al. (2006) demonstrated that apart from the expansion of NK cells $\left(\mathrm{CD} 16^{+} \mathrm{CD}^{-} 6^{-}\right)$, higher levels of pro-inflammatory monocytes $\left(\mathrm{CD} 14^{+} \mathrm{CD} 16^{+} \mathrm{HLA}-\mathrm{DR}^{++}\right)$ were also observed during early indeterminate Chagas disease. These authors suggested that the activation of the innate immune response during early human Chagas disease, through recruitment of NK cells $\left(\mathrm{CD} 16^{+} \mathrm{CD} 56^{-}\right)$ and the activation of monocytes, could be an important bridge between innate and adaptive immunological events in early $T$. cruzi infection.

These data are consistent with those from experimental models in which $T$. cruzi-derived antigens are able to activate NK cells before the development of Tcell-mediated immunity (Brener \& Gazzinelli 1997). During experimental T. cruzi infection, NK cells have emerged as an important cell population associated with the defence against the spread of the parasitic infection (Brener \& Gazzinelli 1997). The classic mechanism proposed for the acute phase of infection involves $T$. cruzi triggering the synthesis of IL-12 by macrophages, which elicits the synthesis of IFN- $\gamma$ by NK cells (Gazzinelli et al. 1993). This cytokine will in turn augment IL-12 and TNF- $\alpha$ synthesis as well as oxide nitric production by macrophage/monocytes contributing to parasite clearance (Camargo et al. 1997). Thus, NK cells are an important source of IFN- $\gamma$ before the development of T cell-mediated immunity.

It is important to point out that the strong and uncontrolled activation of NK cells, as well as pro-inflammatory monocytes, may also lead to tissue damage leading to the development of severe chronic disease. Thus, the establishment of immunoregulatory mechanisms seems to be important for controlling immune activity and preventing the deleterious effects associated with excessive stimulation of the immune system, which may lead to high levels of morbidity. In this context, the cytokine milieu produced by these cells may represent an important regulatory mechanism. The analysis of pro and anti-inflammatory cytokine profiles of circulating monocytes and NK cells has recently been reported by Sathler-Avelar et al. (2006). Despite a slight increase in IL-12+ monocytes, equivalent numbers of TNF- $\alpha^{+}$and IL- $10^{+}$monocytes, as well as IFN- $\gamma^{+}, \mathrm{TNF}-\alpha^{+}$and IL- $4^{+}$ NK cells, demonstrated that the ex vivo cytokine profile of monocytes and NK cells during early indeterminate Chagas disease resembled that observed in healthy uninfected children. However, a shift towards a mixed cytokine profile was observed in NK cells upon in vitro stimulation with $T$. cruzi antigens, leading to higher levels of IFN- $\gamma^{+}$, TNF- $\alpha^{+}$, and IL- $4^{+}$cells. These findings may suggest that NK cells could provide protection against $T$. cruzi in early indeterminate Chagas disease, favouring the generation of effective and non-deleterious inflammatory mechanisms (Sathler-Avelar et al. 2006). 


\section{Innate immune response during late chronic Cha- gas disease}

Despite the fact that the adaptive immune response has been considered for decades as the most important protector mechanism during chronic infection (Dutra et al. 1994, 1996, Lemos et al. 1998, Gomes et al. 2003, 2005, Souza et al. 2004), recent studies have suggested the importance of the innate immune response as a significant regulatory mechanism for controlling morbidity during chronic disease (Vitelli-Avelar et al. 2005). Vitelli-Avelar et al. (2005) have demonstrated that despite observing an increased frequency of circulating NK cells in all chronic Chagas disease patients, the percentage of $\mathrm{CD}^{-} \mathrm{CD} 16^{+} \mathrm{CD} 56^{+}$and $\mathrm{CD} 3{ }^{-} \mathrm{CD} 16^{+} \mathrm{CD} 56^{\mathrm{dim}}$ NK cell subsets is particularly high in indeterminate patients (IND), suggesting a possible protective role of these NK cells subsets in controlling morbidity during chronic Chagas disease. Phenotypic and functional studies have demonstrated that the CD56 ${ }^{\text {dim }}$ NK cells exhibit increased cytotoxic capacity (Lieke et al. 2004), which can supports the hypothesis that this NK cell subset may contribute to effective control of tissue parasitism in IND patients, avoiding the deleterious immune response created by cytotoxic $\mathrm{CD} 8^{+} \mathrm{T}$-cells which is reported in CARD (Dutra et al. 1994, 1996, Lemos et al. 1998, Vitelli-Avelar et al. 2005, 2006). Furthermore, Vitelli-Avelar et al. $(2005,2006)$ have reported that patients with the late indeterminate clinical form of Chagas disease display a high frequency of circulating NKT cells, whereas patients with cardiac disease show basal levels of NKT cells and a negative association with the high frequency of activated $\mathrm{CD} 8^{+} \mathrm{T}$ cells. As NKT cells have been shown to play an important role in modulating the activation of $\mathrm{CD} 8^{+} \mathrm{T}$ cells via apoptosis, as well as throughout the secretion of regulatory cytokines (Godfrey \& Kronenberg et al. 2004, Murray \& Crispe 2004), it is possible that the enhanced frequency of these cells in IND patients further contributes to the control of the deleterious cytotoxic activity mediated by $\mathrm{CD} 8^{+} \mathrm{HLA}-$ $\mathrm{DR}^{+} \mathrm{T}$ cells. The lack of regulatory events in CARD patients may account for the exacerbated immune response that culminates in a strong cytotoxic response by $\mathrm{CD} 8^{+}$ T-cells and subsequent tissue damage. Previous findings regarding histopathological biopsies have already demonstrated a higher frequency of T. cruzi-specific $\mathrm{CD}^{+} \mathrm{T}$ cells in CARD patients, possibly relating to the presence of the parasite antigen (Reis et al. 1993).

Besides the participation of NK and NKT cells in controlling morbidity during late chronic Chagas disease, it has also been suggested that a high frequency of macrophage-like cells (CD14 $\left.4^{+} \mathrm{CD} 16^{+}\right)$may account for the limited tissue damage during chronic infection, favouring the establishment/maintenance of lifelong IND Chagas disease.

Likewise, reports during early chronic Chagas disease have shown that the cytokine milieu produced by monocytes and NK cells represents an important biomarker of Chagas disease morbidity. The analyses of pro and anti-inflammatory cytokine profiles of circulating monocytes and NK cells have recently been reported
(Gomes et al. 2003, Vitelli-Avelar et al. 2008). Gomes et al. (2003) demonstrated that monocytes from IND produce more IL-10 compared to CARD, suggesting that these cells may play an important role in regulating immune response during chronic Chagas disease. On the other hand, CARD patients present a higher ability to produce TNF- $\alpha$, suggesting a role for pro-inflammatory monocytes in the development of cardiac disease (Vitelli-Avelar et al. 2008). These findings corroborate with previous reports analyzing isolated peripheral blood mononuclear cells (PBMC) (Correa-Oliveira et al. 1999, Golgher \& Gazzinelli 2004, Dutra et al. 2005).

\section{Treg cells in early indeterminate and late human Chagas disease}

Amongst the most recently described immunoregulatory mechanisms are the Treg cells, which are phenotypically identified in humans as $\mathrm{CD} 44^{+} \mathrm{CD} 25^{\text {High }} \mathrm{T}$ cells (Baecher-Allan et al. 2001). Treg cells have emerged as a central control point in the modulation of various immune responses, including autoimmune responses and immunity to infectious microbes (Piccirillo 2008). Recently, Brazilian groups have developed pioneer investigations evaluating the frequency of Treg cells during early and late indeterminate Chagas disease (VitelliAvelar et al. 2005, 2006, Araujo et al. 2007). Ex vivo data obtained by those studies have demonstrated that T. cruzi-infected children with indeterminate clinical disease display a lower frequency of $\mathrm{CD} 4{ }^{+} \mathrm{CD} 25^{\mathrm{High}} \mathrm{T}$ cells as compared to non-infected children (Vitelli-Avelar et al. 2006). On the other hand, increased levels of $\mathrm{CD} 4^{+} \mathrm{CD} 25^{\mathrm{High}}$ Treg cells can be observed in the peripheral blood of late chronic IND patients (Vitelli-Avelar et al. 2005), which negatively correlated with the levels of activated $\mathrm{CD}^{+} \mathrm{T}$ cells. These data suggest that the expansion of $\mathrm{CD} 4^{+} \mathrm{CD} 25^{\text {High }}$ Treg cells during late Chagas disease could be a regulatory mechanism, limiting tissue damage and leading to lifelong persistence of the indeterminate clinical form of Chagas disease.

In an attempt to better characterise the Treg cells in Chagas disease, Araujo et al. (2007) have investigated the co-expression of several cell surface markers, as well as intracellular Foxp3 and IL-10 expression, by $\mathrm{CD} 4^{+} \mathrm{CD} 25^{\text {High }}$ cells. The phenotypic and functional aspects of $\mathrm{CD} 4{ }^{+} \mathrm{CD} 25^{\text {High }}$ Treg cells were evaluated before (ex vivo) and after in vitro exposure of whole blood to epimastigote T. cruzi antigens (EPI). Foxp3, which has been shown to play a key role in Treg cell function and represents a highly specific marker for these cells (Hori et al. 2003, Ramsdell 2003), was shown to be expressed by a majority of the $\mathrm{CD} 4^{+} \mathrm{CD} 25^{\text {High }}$ cells from chagasic patients, supporting that this analysis would be a reliable approach for quantifying Treg cells in these patients. Using this strategy, Araujo et al. (2007) demonstrated that increased levels of $\mathrm{CD} 4^{+} \mathrm{CD} 25^{\text {High }}$ Treg cells could be observed in the IND after in vitro exposure of their whole blood to EPI. It was also observed that despite no differences observed in the ex vivo analysis, the in vitro EPI stimuli was able to drive the $\mathrm{CD} 4^{+} \mathrm{CD} 25^{\text {High }}$ Treg cells of all chagasic patients to express a number of cell 
surface markers related to cell activation and migration. In fact, the Treg cells from late IND and CARD showed increased expression of CD69, CD40L and CD54, as well as decreased expression of CD62L and IL-10R. Interestingly, a higher percentage of $\mathrm{CD} 4{ }^{+} \mathrm{CD} 25^{\mathrm{High}} \mathrm{T}$ cells expressing CTLA-4 was observed in the CARD group, whereas an increased frequency of $\mathrm{CD} 44^{+} \mathrm{CD} 25^{\mathrm{High}}$ cells expressing IL-10 was observed in the IND group (Araujo et al. 2007). These findings suggest that Treg cells may be important in controlling the inflammatory response to $T$. cruzi in IND by the expression of IL-10, which contributes to efficient parasite control by effector cells without the development of tissue immunopathology. Despite CTLA-4 being constitutively expressed by Treg cells, the role for this inhibitory signalling molecule in the homeostasis and suppression of the immune response mediated by Treg cells is not yet well-defined. CTLA-4 expression has been associated with the Treg cell production of immunosuppressive cytokines, such as TGF- $\beta$ and IL-10, and is essential for cell-contact suppression in vitro (Read et al. 2000). Several mechanisms in which Treg cells may perform their modulatory activity have been proposed in different disease models, including inhibition of cytotoxic activity by direct antigen-presentation, cell-independent contact with $\mathrm{CD} 8^{+} \mathrm{T}$ cells, or through the production of anti-inflammatory cytokines, such as IL-10 and TGF- $\beta$ (Piccirillo 2008). The molecular and cellular factors that affect Treg cells development, homeostasis, function and consequential immunity to self and non-self antigens are still controversial. Recent studies have shed light on the development of novel methods of disease prevention and treatment by enhancing and reestablishing Treg-mediated control over the immune system in animal models, as well as in human disease (Piccirillo 2008). It is likely that Treg cells employ distinct mechanisms to regulate the immune response in IND and CARD. However, the exact mechanism by which Treg cells participate in the complex host-parasite interaction still remains to be elucidated.

\section{The impact of Chagas disease etiological treatment on innate immunity and Treg cells}

In the last decade, the literature has accumulated evidence that correlates immune response and chemotherapy efficacy (Michailowsky et al. 1998, Urbina 1999, Coura \& de Castro 2002). In murine models, these studies suggest that activation of the immune system enhances Bz treatment efficacy during T. cruzi infection (Michailowsky et al. 1998, Urbina 1999, Coura \& de Castro 2002). In humans, Bahia-Oliveira et al. (2000) have demonstrated that effective chemotherapy is associated with the ability of the host immune system to produce high levels of IFN- $\gamma$. However, despite the fact that activation of a potent inflammatory immune response is related to chemotherapy efficacy, it is worth mentioning that exacerbated activation of the immune system may favour the development of a strong pro-inflammatory response, which is likely observed in patients with cardiac disease (Gomes et al. 2003). In fact, it seems that a fine balance of pro- and anti-inflammatory immune responses may be the key to guaranty parasite clearance, while controlling Chagas disease morbidity, during etiological treatment (Sathler-Avelar et al. 2006). A coherent understanding of the changes in immunological status following Chagas disease etiological treatment will certainly aid in determining new perspectives for therapy, intervention, and management. The analysis of host immunity status pre and post-treatment is essential for elucidating the mechanisms of $\mathrm{Bz}$ action, as well as for supporting the rational development of new trypanosomicidal agents.

The etiological treatment used during early stages of Chagas disease is generally associated with high cure rates and good clinical outcome (Galvão et al. 1993, Mady et al. 2008). Analysis of the immunological changes following the etiological treatment of early Chagas disease has been recently performed (Sathler-Avelar et al. 2006, 2008). These studies demonstrated that an elevated activation state of the innate immunity occurs in chagasic children following Bz-treatment, as observed by enhanced levels of macrophage-like $\left(\mathrm{CD} 14^{+} \mathrm{CD} 16^{+}\right)$ and pro-inflammatory monocytes $\left(\mathrm{CD} 14^{+} \mathrm{HLA}-\mathrm{DR}^{\text {High }}\right)$. However, this augmented monocyte activation state is negatively correlated with the levels of TNF- $\gamma^{+}$and IL-12 ${ }^{+}$monocytes (Sathler-Avelar et al. 2008). These findings may at first sound controversial, since the proinflammatory monocytes have been pointed out as an important source of TNF- $\alpha$ and IL-12 (Belge et al. 2002, Ziegler-Heitbrock 2007). Therefore, it is possible that some immunomodulatory mechanism controls the cytokine synthesis of these cells after Bz-treatment. Sathler-Avelar et al. (2006) demonstrated that immunomodulatory mechanisms established mainly in the adaptive immune compartment, mediated by IL-10 derived from $\mathrm{CD}^{+} \mathrm{T}$-cells and B-cells, may control the immunological events following Bz-treatment of infected children. These findings re-enforce the importance of the interplay between innate and adaptive immunity in the control of exacerbated harmful immune responses, which would result in tissue damage.

Sathler-Avelar et al. (2006) have also demonstrated that Bz-treatment of infected children leads to increased levels of activated NK cells in the peripheral blood. This strong NK cell activation state was correlated with a mixed cytokine pattern characterised by simultaneous synthesis of pro-inflammatory and modulatory cytokines (IFN- $\gamma^{+}$and $\mathrm{IL}-4^{+} \mathrm{NK}$ cells). These findings suggest that a non-polarised immune response is also an important event following etiological treatment during early Chagas disease. Furthermore, these findings support the hypothesis that the presence of activated immune cells is not sufficient to limit etiological treatment, since a mixed pro-/anti-inflammatory cytokine profile supports the existence of a balanced immunological state after Bz-treatment during early Chagas disease.

Analysis of Treg cells have been performed before and after the etiological treatment of early and late Chagas disease. The major findings of these studies did not highlight any significant differences during early or late indeterminate Chagas disease (Antas et al. 2009). On the other hand, it has been reported that Bz-treatment was 
able to increase peripheral blood $\mathrm{CD} 4^{+} \mathrm{CD} 25^{\text {High }}$ Treg cells in treated CARD (Antas et al., unpublished observations) suggesting that these cells could help to prevent additional tissue damage and possible deleterious events associated with the etiological treatment of symptomatic patients. The putative role of regulatory cells during treatment is still unknown and further studies are being developed to better characterise this response.

In summary, these studies suggest that the balanced activation of the innate immune response, apart from Treg cells, may play a role in controlling the adverse events associated with massive antigen release induced by trypanosomicidal agents during etiological treatment. These protective events may control the tissue damage, diminishing and/or modifying the inflammatory nature of the immune response elicited by the $T$. cruzi antigens released by drug intervention.

\section{ACKNOWLEDGEMENTS}

To the Programa de Desenvolvimento Tecnológico em Insumos para a Saúde-PDTIS/FIOCRUZ, for use of its facilities.

\section{REFERENCES}

Antas PRZ, Araujo FF, Vitelli-Avelar DM, Gomes JAS, SathlerAvelar R, Teixeira-Carvalho A, Elói-Santos SM, Pinho RT, Correa-Oliveira R, Martins-Filho AO 2009. Revisiting regulatory T cells: implications for the pathogenesis and management of human infections with emphasis in Chagas' disease. Microbes Infect, in press.

Araujo FF, Gomes JA, Rocha MO, Williams-Blangero S, Pinheiro VM, Morato MJ, Correa-Oliveira R 2007. Potential role of $\mathrm{CD} 4{ }^{+} \mathrm{CD} 25^{\mathrm{HIGH}}$ regulatory T cells in morbidity in Chagas disease. Front Biosci 12: 2797-2806.

Baecher-Allan C, Brown JA, Freeman GJ, Hafler DA 2001. $\mathrm{CD} 4{ }^{+} \mathrm{CD} 25^{\text {High }}$ regulatory cells in human peripheral blood. J Immunol 167: 1245-1253.

Bahia-Oliveira LM, Gomes JA, Cançado JR, Ferrari TC, Lemos EM, Luz ZM, Moreira MC, Gazzinelli G, Correa-Oliveira R 2000. Immunological and clinical evaluation of chagasic patients subjected to chemotherapy during the acute phase of Trypanosoma cruzi infection 14-30 years ago. J Infect Dis 182: 634-638.

Belge KU, Dayyani F, Horelt A, Siedlar M, Frankenberger M, Frankenberger B, Espevik T, Ziegler-Heitbrock L 2002. The proinflammatory $\mathrm{CD} 14^{+} \mathrm{CD} 16^{+} \mathrm{DR}^{++}$monocytes are a major source of TNF. J Immunol 168: 3536-3542.

Bonney KM, Engman DM 2008. Chagas heart disease pathogenesis: one mechanism or many? Curr Mol Med 8: 510-518.

Brener Z, Gazzinelli RT 1997. Immunological control of Trypanosoma cruzi infection and pathogenesis of Chagas' disease. Int Arch Allergy Immunol 114: 103-110.

Buscaglia CA, Di Noia JM 2003. Trypanosoma cruzi clonal diversity and the epidemiology of Chagas disease. Microbes Infect 5: 419-427.

Camargo MM, Andrade AC, Almeida IC, Travassos LR, Gazzinelli RT 1997. Glycoconjugates isolated from Trypanosoma cruzi but not from Leishmania species membranes trigger nitric oxide synthesis as well as microbicidal activity in IFN-gamma-primed macrophages. J Immunol 159: 6131-6139.

Correa-Oliveira R, Gomes J, Lemos EM, Cardoso GM, Reis DD, Adad S, Crema E, Martins-Filho OA, Costa MO, Gazzinelli G, Bahia-Oliveira LM 1999. The role of the immune response on the development of severe clinical forms of human Chagas disease. Mem Inst Oswaldo Cruz 94 (Suppl. I): 253-255.

Coura JR, de Castro SL 2002. A critical review on Chagas disease chemotherapy. Mem Inst Oswaldo Cruz 97: 3-24.

da Silveira AB, Correa-Oliveira R, Matsuyama H, de Oliveira EC, Neto SG, Luquetti AO, Furness JB, d'Avila Reis D 2008. Decreased expression of IK channels in neurons from enteric nervous system is associated with the development of chagasic megacolon. Hum Pathol 39: 1406-1407.

Dutra WO, Martins-Filho OA, Cançado JR, Pinto-Dias JC, Brener Z, Freeman Júnior GL, Colley DG, Gazzinelli G, Parra JC 1994. Activated $\mathrm{T}$ and $\mathrm{B}$ lymphocytes in peripheral blood of patients with Chagas' disease. Int Immunol 6: 499-506.

Dutra WO, Martins-Filho OA, Cançado JR, Pinto-Dias JC, Brener Z, Gazzinelli G, Carvalho JF, Colley DG 1996. Chagasic patients lack CD28 expression on many of their circulating T lymphocytes. Scand J Immunol 43: 88-93.

Dutra WO, Rocha MO, Teixeira MM 2005. The clinical immunology of human Chagas disease. Trends Parasitol 21: 581-587.

Galvão LM, Nunes RM, Cançado JR, Brener Z, Krettli AU 1993. Lytic antibody titre as a means of assessing cure after treatment of Chagas disease: a 10 years follow-up study. Trans $R$ Soc Trop Med Hyg 87: 220-223.

Gazzinelli RT, Hieny S, Wynn TA, Wolf S, Sher A 1993. Interleukin 12 is required for the T-lymphocyte-independent induction of interferon gamma by an intracellular parasite and induces resistance in T-cell-deficient hosts. Proc Natl Acad Sci USA 90: 6115-6119.

Godfrey DI, Kronenberg M 2004. Going both ways: immune regulation via CD1d-dependent NKT cells. J Clin Invest 114: 1379-1388.

Golgher D, Gazzinelli RT 2004. Innate and acquired immunity in the pathogenesis of Chagas' disease. Autoimmunity 37: 399-409.

Gomes JA, Bahia-Oliveira LM, Rocha MO, Busek SC, Teixeira MM, Silva JS, Correa-Oliveira R 2005. Type 1 chemokine receptor expression in Chagas' disease correlates with morbidity in cardiac patients. Infect Immun 73: 7960-7966.

Gomes JA, Bahia-Oliveira LM, Rocha MO, Martins-Filho OA, Gazzinelli G, Correa-Oliveira R 2003. Evidence that development of severe cardiomyopathy in human Chagas' disease is due to a Th1-specific immune response. Infect Immun 71: 1185-1193.

Hontebeyrie-Joskowicz M, Minoprio P 1991. Chagas' disease: Trypanosoma cruzi vs. the host immune system. Res Immunol 142: 125-126.

Hori S, Nomura T, Sakaguchi S 2003. Control of regulatory T cell development by the transcription factor Foxp3. Science 299: 1057-1061.

Lemos EM, Reis D, Adad SJ, Silva GC, Crema E, Correa-Oliveira R 1998. Decreased CD4(+) circulating T lymphocytes in patients with gastrointestinal Chagas disease. Clin Immunol Immunopathol 88: 150-155.

Lieke T, Graefe SE, Klauenberg U, Fleischer B, Jacobs T 2004. NKcells contribute to the control of Trypanosoma cruzi infection by killing free parasites by perforin-independent mechanisms. Infect Immun 72: 6817-6825.

Macedo AM, Machado CR, Oliveira RP, Pena SD 2004. Trypanosoma cruzi: genetic structure of populations and relevance of genetic variability to the pathogenesis of Chagas disease. Mem Inst Oswaldo Cruz 99: 1-12.

Mady C, Ianni BM, de Souza JL Jr 2008. Benznidazole and Chagas disease: can an old drug be the answer to an old problem? Expert Opin Investig Drugs 17: 1427-1433. 
Marinho CR, D’Império Lima MR, Grisotto MG, Alvarez JM 1999. Influence of acute-phase parasite load on pathology, parasitism, and activation of the immune system at the late chronic phase of Chagas' disease. Infect Immun 67: 308-318.

Michailowsky V, Murta SM, Carvalho-Oliveira L, Pereira ME, Ferreira LR, Brener Z, Romanha AJ, Gazzinelli RT 1998. Interleukin-12 enhances in vivo parasiticidal effect of benznidazole during acute experimental infection with a naturally drug-resistant strain of Trypanosoma cruzi. Antimicrob Agents Chemother 42: 2549-2556.

Murray DA, Crispe IN 2004. TNF-alpha controls intrahepatic T cell apoptosis and peripheral T cell numbers. J Immunol 173: 2402-2409.

Piccirillo CA 2008. Regulatory T cells in health and disease. Cytokine 43: 395-401.

Ramsdell F 2003. FOXP3 and natural regulatory T cells: key to a cell lineage? Immunity 19: 165-168.

Read S, Malmström V, Powrie F 2000. Cytotoxic T lymphocyte-associated antigen 4 plays an essential role in the function of $\mathrm{CD} 25(+)$ $\mathrm{CD} 4(+)$ regulatory cells that control intestinal inflammation. J Exp Med 192: 295-302.

Reis DD, Jones EM, Tostes S Jr, Lopes ER, Gazzinelli G, Colley DG, McCurley TL 1993. Characterization of inflammatory infiltrates in chronic chagasic myocardial lesions: presence of tumor necrosis factor-alpha+ cells and dominance of granzyme A+, CD8+ lymphocytes. Am J Trop Med Hyg 48: 637-644.

Samudio M, Montenegro-James S, Cabral M, Martinez J, Rojas de Arias A, James MA 1998. Cytokine responses in Trypanosoma cruzi infected children in Paraguay. Am J Trop Med Hyg 58: 119-121.

Sathler-Avelar R, Lemos EM, Reis DD, Medrano-Mercado N, Araújo-Jorge TC, Antas PR, Corrêa-Oliveira R, Teixeira-Carvalho A, Elói-Santos SM, Favato D, Martins-Filho OA 2003. Phenotypic features of peripheral blood leucocytes during early stages of human infection with Trypanosoma cruzi. Scand J Immunol 58: 655-663.

Sathler-Avelar R, Vitelli-Avelar DM, Massara RL, Borges JD, Lana M, Teixeira-Carvalho A, Dias JC, Elói-Santos SM, Martins-Filho OA 2006. Benznidazole treatment during early-indeterminate Chagas' disease shifted the cytokine expression by innate and adaptive immunity cells toward a type 1-modulated immune profile. Scand J Immunol 64: 554-563.

Sathler-Avelar R, Vitelli-Avelar DM, Massara RL, de Lana M, Pinto Dias JC, Teixeira-Carvalho A, Elói-Santos SM, Martins-Filho
OA 2008. Etiological treatment during early chronic indeterminate Chagas disease incites an activated status on innate and adaptive immunity associated with a type 1-modulated cytokine pattern. Microbes Infect 10: 103-113.

Souza PE, Rocha MO, Rocha-Vieira E, Menezes CA, Chaves AC, Gollob KJ, Dutra WO 2004. Monocytes from patients with indeterminate and cardiac forms of Chagas' disease display distinct phenotypic and functional characteristics associated with morbidity. Infect Immun 72: 5283-5291.

Teixeira MM, Gazzinelli RT, Silva JS 2002. Chemokines, inflammation and Trypanosoma cruzi infection. Trends Parasitol 18: 262-265.

Umezawa ES, Stolf AM, Corbett CE, Shikanai-Yasuda MA 2000. Chagas disease. Lancet 357: 797-799.

Urbina JA 1999. Chemotherapy of Chagas' disease: the how and the why. J Mol Med 77: 332-338.

Vago AR, Andrade LO, Leite AA, d'Avila Reis D, Macedo AM, Adad SJ, Tostes S Jr, Moreira MC, Filho GB, Pena SD 2000. Genetic characterization of Trypanosoma cruzi directly from tissues of patients with chronic Chagas disease: differential distribution of genetic types into diverse organs. Am J Pathol 156: 1805-1809.

Vitelli-Avelar DM, Sathler-Avelar R, Dias JC, Pascoal VP, Teixeira-Carvalho A, Lage PS, Elói-Santos SM, Corrêa-Oliveira R, Martins-Filho OA 2005. Chagasic patients with indeterminate clinical form of the disease have high frequencies of circulating $\mathrm{CD}^{+}{ }^{+} \mathrm{CD} 166^{-} \mathrm{CD} 56^{+}$natural killer T cells and $\mathrm{CD} 4{ }^{+} \mathrm{CD} 25^{\text {High }}$ regulatory T lymphocytes. Scand J Immunol 62: 297-308.

Vitelli-Avelar DM, Sathler-Avelar R, Massara RL, Borges JD, Lage PS, Lana M, Teixeira-Carvalho A, Dias JC, Elói-Santos SM, Martins-Filho OA 2006. Are increased frequency of macrophage-like and natural killer (NK) cells, together with high levels of NKT and $\mathrm{CD} 4{ }^{+} \mathrm{CD} 25^{\text {High }} \mathrm{T}$ cells balancing activated $\mathrm{CD} 8^{+} \mathrm{T}$ cells, the key to control Chagas' disease morbidity? Clin Exp Immunol 145: 81-92.

Vitelli-Avelar DM, Sathler-Avelar R, Teixeira-Carvalho A, Pinto Dias JC, Gontijo ED, Faria AM, Elói-Santos SM, Martins-Filho OA 2008. Strategy to assess the overall cytokine profile of circulating leukocytes and its association with distinct clinical forms of human Chagas disease. Scand J Immunol 68: 516-525.

Weekly ER 2007. New global efforts to eliminate Chagas disease. Report. WER 82: 259-260.

Ziegler-Heitbrock L 2007. The CD14 ${ }^{+} \mathrm{CD} 6^{+}$blood monocytes: their role in infection and inflammation. J Leukoc Biol 81: 584-592. 